\title{
Epiretinal membrane in a subject after transvitreal delivery of palucorcel (CNTO 2476)
}

\author{
This article was published in the following Dove Press journal: \\ Clinical Ophthalmology \\ 6 October 2017 \\ Number of times this article has been viewed
}

\author{
Rand Spencer ${ }^{\prime}$ \\ Steven Fisher ${ }^{2}$ \\ Geoffrey P Lewis ${ }^{3}$ \\ Terri Malone ${ }^{4}$ \\ 'Texas Retina Associates, Dallas, \\ TX, USA; ${ }^{2}$ Molecular, Cellular, and \\ Developmental Biology, ${ }^{3}$ Center for \\ the Study of Macular Degeneration, \\ Neuroscience Research Institute, \\ University of California, Santa \\ Barbara, CA, ${ }^{4}$ Cell Therapy, Janssen \\ Research \& Development, LLC, Spring \\ House, PA, USA
}

Background: A 70-year-old woman with retinitis pigmentosa experienced an epiretinal membrane (ERM) formation and a tractional retinal detachment (RD) following subretinal administration of palucorcel (CNTO 2476), a novel human umbilical tissue-derived cell-based therapy, as part of a Phase I study. The clinical course and results of a histologic examination of the ERM, which was peeled during surgery to repair the RD, are described here.

Methods: In this open-label, first-in-human, Phase I study (NCT00458575), two of seven subjects developed RD, with an ERM formation reported in a woman receiving a targeted dose of $3.0 \times 10^{5}$ palucorcel administered via a transvitreal route. A sample of the ERM was retained for analysis following the ERM peeling procedure. Clinical outcomes and ERM histology, based on immunocytochemistry analyses and fluorescence in situ hybridization (FISH) staining, were evaluated.

Results: We first noted the RD and formation of the ERM at 26 days after palucorcel administration. The ERM was cellular and contained multiple cell types, including Müller glial cells, immune cells, neurites, retinal pigment epithelial cells, and palucorcel. The majority of cells were not actively dividing. FISH staining showed a subset of Y chromosome-positive cells in the ERM from this woman, supporting the presence of palucorcel (derived from umbilical cord tissue of male neonate). Palucorcel did not differentiate into Müller glia, immune cells, neurites, or retinal pigment epithelial cells.

Discussion: The development of an ERM containing both subject (self) cells and palucorcel suggests that palucorcel egress in the vitreal cavity after retinotomy may contribute to ERM formation and RD and that an alternative delivery method will be required before further studies are conducted. Subsequent clinical research using alternative subretinal delivery methods for palucorcel in other indications suggests that membrane development does not occur when palucorcel is delivered without retinal perforation.

Keywords: cell therapy, epiretinal membrane, retinitis pigmentosa

\section{Plain language summary}

There are currently no effective treatments for retinitis pigmentosa (RP), a progressive disease of the eye in which retinal cells are destroyed, resulting in vision loss. Palucorcel is a new cell therapy product derived from human umbilical tissue that has been shown to reduce the destruction of the retina and corresponding loss of vision in rats. The effects of palucorcel delivered subretinally in subjects with advanced RP were evaluated in a Phase I study, the first study of palucorcel in humans. A retinal detachment (RD), a serious complication in which the retina pulls away from the surrounding tissue, occurred at 1 month after surgical application of palucorcel in two of seven study subjects; these RDs required surgical treatment. One of these two subjects who experienced a partial RD also developed an epiretinal membrane (ERM), a thin sheet of fibrous tissue on the surface of the retina. We analyzed a sample of this ERM, which was shown to include immune cells, Müller glial cells, and retinal pigmented epithelial cells
Correspondence: Terri Malone Janssen Cell Therapy, Welsh and McKean Roads, Spring House, PA 19477, USA

$\mathrm{Tel}+$ I 4845719709

Email tmalone2@its.jnj.com (c) (1) (2) 2017 Spencer et al. This work is published and licensed by Dove Medical Press Limited. The full terms of this license are available at https://www.dovepress.com/terms.php (c)
hereby accept the Terms. Non-commercial uses of the work are permitted without any further permission from Dove Medical Press Limited, provided the work is properly attributed. For permission hereby accept the Terms. Non-commercial uses of the work are permitted without any further permission from Dove M
for commercial use of this work, please see paragraphs 4.2 and 5 of our Terms (https://www.doveperess.com/terms.php). 
from the patient, as well as palucorcel. These findings suggest that a different method of delivering palucorcel is needed to prevent the development of ERM and RD.

\section{Introduction}

Retinitis pigmentosa (RP) is a gradually progressive and irreversible ocular disease characterized by the degeneration of photoreceptors and a progressive loss of peripheral and central vision. ${ }^{1}$ There are currently no effective treatments for RP that can stop or reverse the disease; thus, there is an urgent need for the development of novel therapies for these patients. ${ }^{1}$ Palucorcel (CNTO 2476) is a proprietary cryopreserved matrix-free suspension of human umbilical tissue-derived cells (hUTCs). This product is a fully differentiated cell line of mesenchymal origin that is expanded in culture and cryopreserved as a therapeutic product. Palucorcel is thought to provide trophic factors that may have a therapeutic effect on vision loss when administered to the subretinal space. ${ }^{2}$ During a preclinical trial, palucorcel reduced the rate of retinal degeneration and vision loss in a rat model $^{3}$ of human retinal disease (Royal College of Surgeons [RCS] rat). In the RCS rat model, subretinally administered palucorcel was confined to the subretinal space, the cells did not differentiate, and there was no evidence of tumor formation. ${ }^{4}$

Based on data from the rat model, the preliminary safety and immunogenicity of subretinally administered palucorcel was evaluated in a subsequent open-label, first-in-human, Phase I study in seven subjects with RP (ClinicalTrials. gov Identifier: NCT00458575; registered April 10, 2007). To enter the study, subjects must have had advanced RP with visual acuity characterized by either "light perception (LP) only" or "no better than hand motion." No genetic testing was required for enrolled subjects. After achieving adequate anesthesia, study surgeons performed a three-port pars plana vitrectomy, followed by induction of a posterior vitreous detachment. Study surgeons then administered a single targeted dose of palucorcel in phosphate-buffered saline (PBS; total volume, $100 \mu \mathrm{L}$ ) at least 1 disc diameter from the temporal side of the macula in one eye. The cells were injected into the subretinal space via a transvitreal route over a period of 80 seconds using a 275-micron microcatheter. The needle tip was placed away from the opening and positioned to direct injected cells distal to the retinotomy site and minimize cell reflex from the bleb to the vitreous. Five subjects received $6.0 \times 10^{4}$ cells, one subject received $3.0 \times 10^{5}$ cells, and one subject received $5.6 \times 10^{5}$ cells. For this study, surgeons could complete a fluid-air exchange at the end of the infusion at their discretion and close the incisions based on their preference. Subjects received standard postoperative care as prescribed following a threeport pars plana vitrectomy, including cycloplegic drops (eg, atropine 1\%) twice per day, prednisolone acetate $1 \%$ drops 4 times per day, and the surgeon's choice of a topical antibiotic. No immunosuppressant medication was required. Subjects were followed up for 5 years.

The study was conducted in accordance with the ethical principles of the Declaration of Helsinki, and informed consent was obtained from all subjects. The study protocol and all amendments were approved by local institutional review boards at Oregon Health and Science University, Baylor Research Institute, Baylor University Medical Center Dallas, and the University of Miami.

We noted retinal detachments (RDs) requiring surgical treatment at 1 month in two subjects who received different palucorcel doses (ie, $3.0 \times 10^{5}$ or $5.6 \times 10^{5}$ cells). Visual acuity in both subjects returned to baseline (LP) upon reattachment. Based on the high rate of RDs in this small study, the sponsor terminated further enrollment into this study and elected to develop an alternative delivery system.

One subject who received the $3.0 \times 10^{5}$ dose developed a localized, tractional RD in conjunction with an epiretinal membrane (ERM). This case report describes the clinical outcome and histologic evaluation of the ERM in the subject who experienced the localized tractional RD.

\section{Case report of RD with an ERM formation}

\section{Subject characteristics and treatment delivery}

The subject was a 70-year-old woman with RP and an ongoing history of posterior subcapsular cataract and visual discomfort from glare. The subject was targeted to receive palucorcel at a dose of $3.0 \times 10^{5}$ cells; however, the actual dose received was $2.22 \times 10^{5}$ cells, which was within specifications. A fluid-air exchange was not performed; however, a small air bubble remained at the retinotomy site opening at the completion of the injection and acted like a ball valve (Figure 1).

We first noted the formation of the ERM and RD in this subject at 26 days after the administration of palucorcel. $\mathrm{RD}$ was considered related to the transvitreal delivery procedure and probably related to the treatment (palucorcel). Fundus photographs of the subject's eye prior to the procedure are shown in Figure 2A and B, and fundus photographs at 5 weeks after surgery (showing the RD and ERM) are shown in Figure 2C and D. 


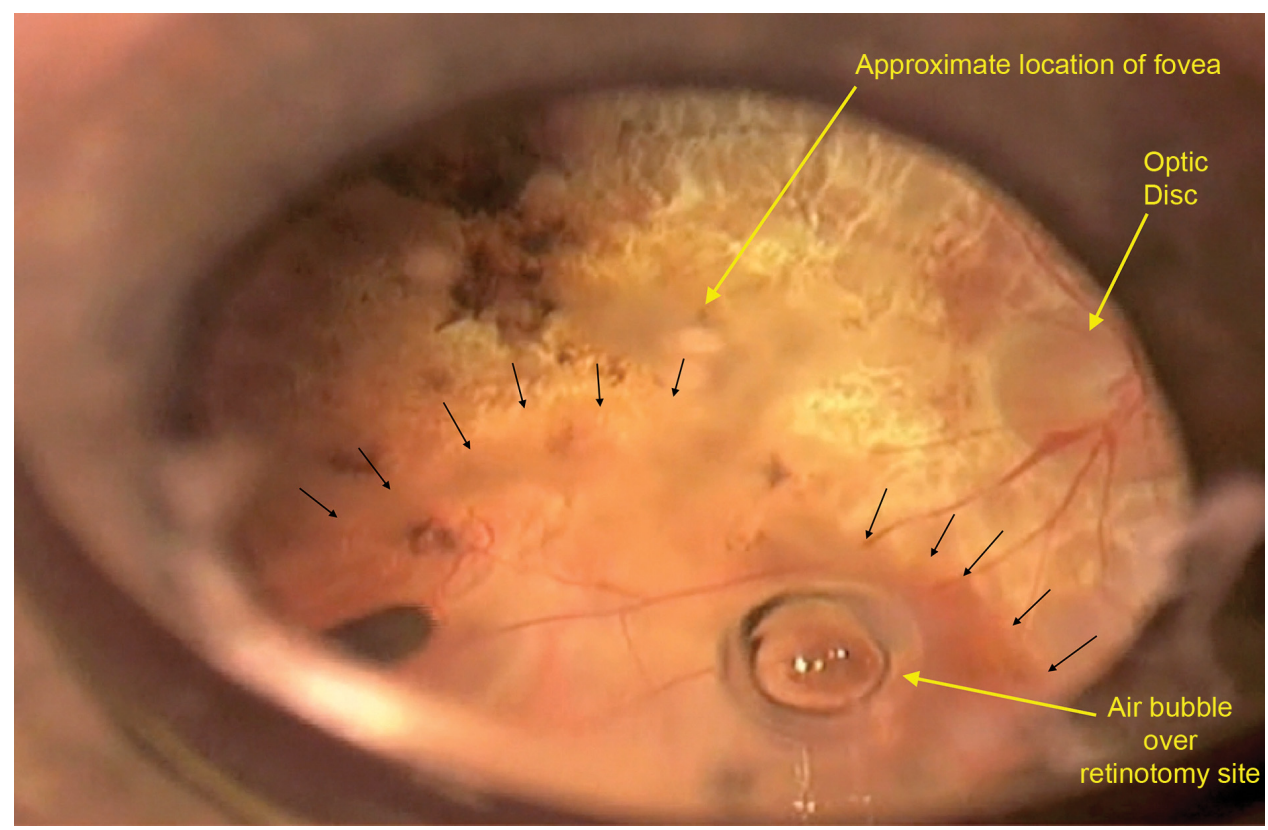

Figure I Appearance of subretinal bleb containing palucorcel injection immediately after completion of the injection of the cellular product at the time of surgery. Notes: Note the small air bubble at the opening of the retinotomy site. Short, black arrows demarcate the edge of the subretinal bleb of injected palucorcel.
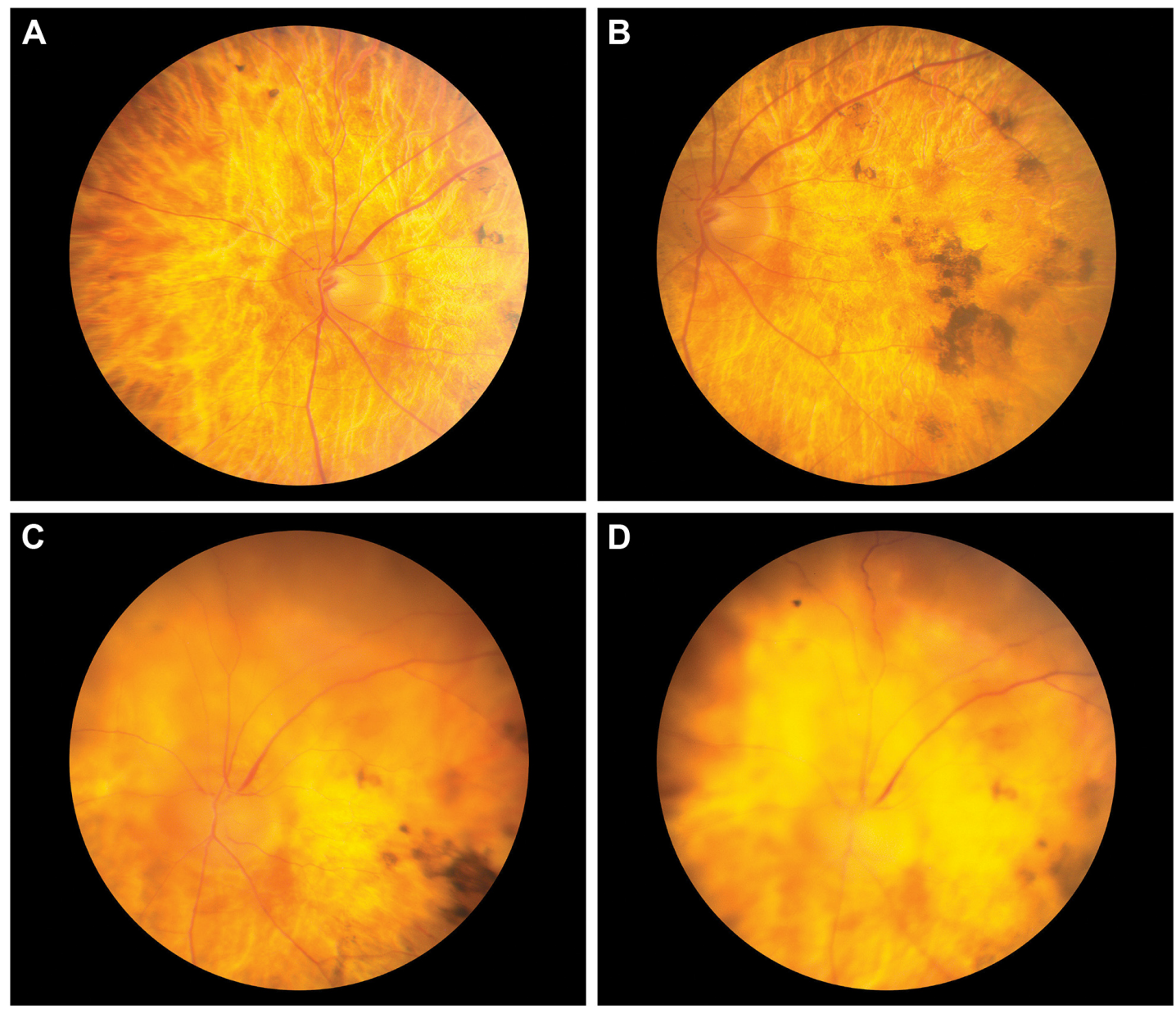

Figure 2 Fundus photographs of the subject's eye (A, B) before the procedure and (C, D) at 5 weeks after surgery. ${ }^{2}$ Note: ${ }^{2}$ The area of retinal detachment can be seen superior to the optic disc. 


\section{ERM analysis}

We performed an ERM peeling to reattach the retina and to recover a tissue sample for histologic examination. The membrane was preserved in a cold solution of $4 \%$ paraformaldehyde and then divided into three equal parts $(\sim 3 \mathrm{~mm}$ each) for analysis; two parts were processed for immunocytochemistry. For the initial immunocytochemistry analysis, the two separate pieces of tissue were rinsed in PBS, blocked in normal donkey serum (1:20) in PBS containing 0.5\% bovine serum albumin, $0.1 \%$ Triton $\mathrm{X}-100$, and $0.1 \%$ azide (PBTA) overnight at $4{ }^{\circ} \mathrm{C}$, and then incubated with primary antibodies (also in PBTA) overnight. The probes used for one piece of tissue included the following: anti-vimentin (1:1,000, Millipore, Temecula, CA, USA) to identify Müller cells, anti-neurofilament (1:500, Abcam, Cambridge, MA, USA) to identify ganglion cell neurites, and biotinylated ricinus communis (1:1,000, 60 kD; Vector Labs, Burlingame, CA, USA) to identify microglia and macrophages. The second piece of tissue was also labeled with vimentin and ricinus communis but additionally included anti-ezrin (1:1,000; Sigma, St Louis, MO, USA) to identify retinal pigment epithelial (RPE) cells. After rinsing the primary antibodies in PBTA, the secondary antibodies, conjugated to cyanine (Cy) $\mathrm{Cy} 2, \mathrm{Cy} 3$, or Cy5 (1:200 in PBTA; Jackson ImmunoResearch, West Grove, PA, USA), were added together overnight at $4^{\circ} \mathrm{C}$. On the final day, samples were rinsed in PBTA, and a Hoescht nuclear stain was added at 1:5,000 for 10 minutes. Because anti-vimentin can identify both Müller cells and donor cells, the first piece of tissue was then restained to look more specifically for glial cells and dividing cells using anti-glial fibrillary acidic protein (GFAP; 1:400; DAKO, Carpinteria, CA, USA), and the second piece of tissue was restained with anti-Mib1 (1:100; Immunotech, Beckman Coulter, Fullerton, CA, USA) to identify dividing cells. After overnight incubation and subsequent rinsing in PBTA, the secondary antibodies conjugated to $\mathrm{Cy} 3$ were added overnight. The next day, the samples were rinsed in PBTA and then mounted onto glass slides using $5 \%$ n-propyl gallate in glycerol and viewed on an Olympus FV1000 confocal microscope (Melville, NY, USA).

The initial staining showed that the ERM contained glial cells, immune cells, neurites, and RPE cells and appeared relatively typical of other human ERMs. The membrane was primarily composed of a central mass of Müller glial cells and possibly palucorcel, based on anti-vimentin labeling; anti-vimentin was shown to identify both Müller cells and palucorcel. We found a focal region that contained neurites, but these were not widespread (Figure 3A and B). Immune cells, including macrophages and some microglia, were scattered throughout the tissue. RPE cells were also scattered throughout the tissue but were primarily located at the peripheral edges of the membrane (Figure $3 \mathrm{C}$ and D). The results of subsequent staining with anti-GFAP (to identify glia) and anti-Mib1 (to identify dividing cells) revealed many GFAP-positive glia throughout the tissue (double-labeled with anti-vimentin). There was a population of anti-vimentinlabeled cells that were not labeled with anti-GFAP, which were most likely the injected palucorcel (Figure 4A and B). The majority of cells were not actively dividing, based on the low level of Mib1 staining (Figure 4C and D).

Because palucorcel was derived from the umbilical cord of a male neonate and this subject was a woman, the third part of the unstained membrane was evaluated using $\mathrm{X}$ and $\mathrm{Y}$ chromosome fluorescence in situ hybridization staining. ${ }^{5}$ Point probes were used for human chromosomes $\mathrm{X}$ (green) and $\mathrm{Y}$ (red) on normal human control metaphase chromosomes and on a normal human tissue section. To further improve the quality of hybridization in the ERM tissue, the samples were subjected to a permeabilization treatment that included the use of more concentrated protease and larger amounts of pepsin for protein digestion. This analysis revealed that a subset of the cells were Y chromosome positive, indicating the presence of palucorcel in the ERM (Figure 5). However, the amount of material available for analysis was limited, which made it difficult to assess the relative proportion of palucorcel in the membrane.

\section{Conclusion}

Palucorcel is a potential therapy for atrophic macular degeneration, but the potential for ocular adverse effects is still under investigation. This case demonstrates the potential for $\mathrm{RD}$ and ERM formation when palucorcel is administered via retinotomy with reflux of cells into the vitreous.

The current ERM analysis showed that the membrane was cellular in nature and composed of multiple cells types, including Müller glia, macrophages/microglia, and vimentin-positive/GFAP-negative cells (likely palucorcel). The majority of the cells were not actively dividing, as evidenced by the lack of Mib1 staining. It is worthwhile to consider that cell proliferation is a common event in ERMs, which may represent an aberrant form of the healing response, with contraction following the initial proliferation phase. ${ }^{6}$ Furthermore, ganglion cell neurites are often identified in human subretinal membranes and ERM. ${ }^{7}$ It appears that palucorcel comingles with native RPE and immune cells when permitted to reflux to the vitreous following delivery of palucorcel through a retinotomy.

The safety of cell therapy must be considered as a combination of the safety of the surgical procedure and the 

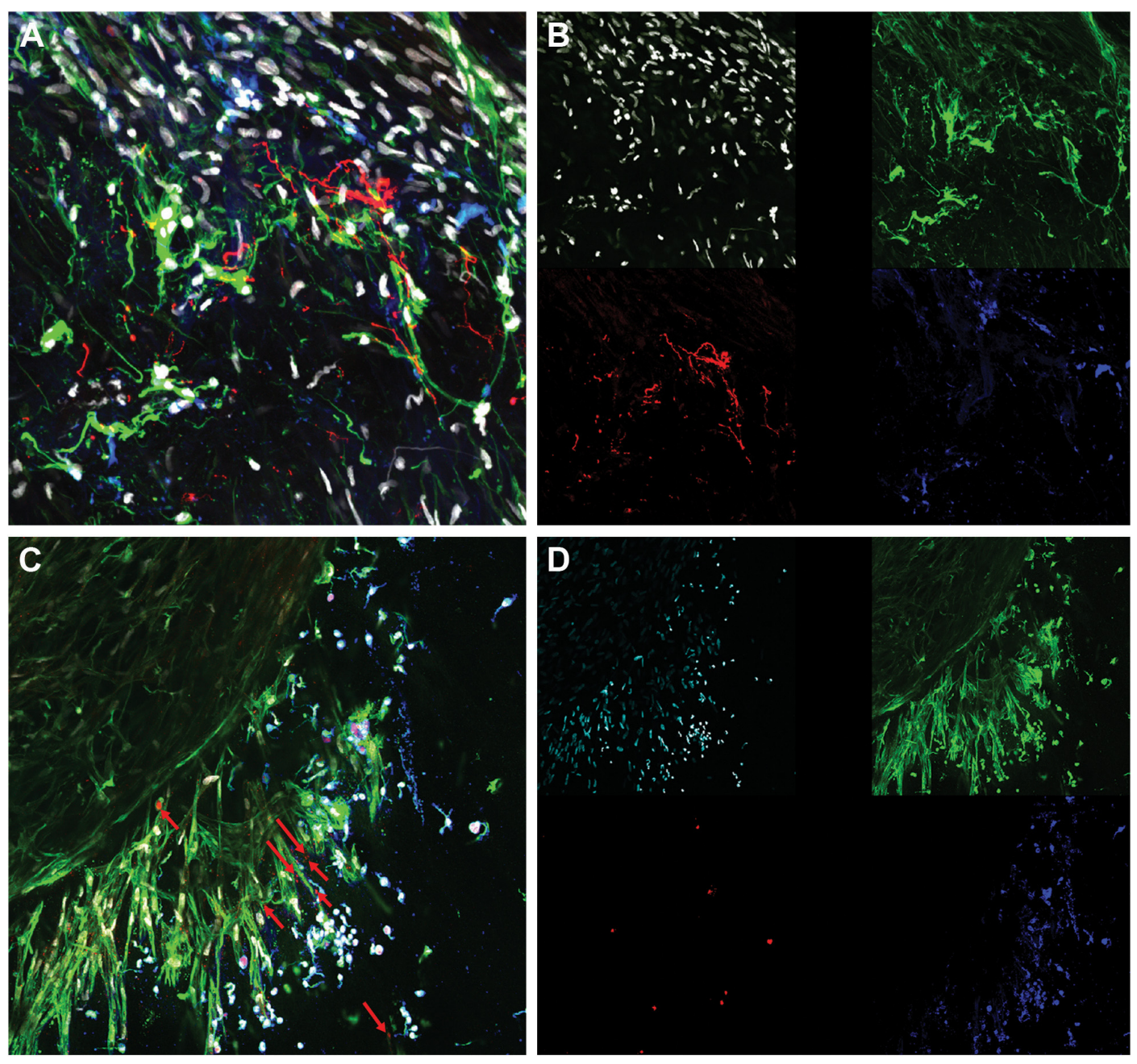

Figure 3 Epiretinal membrane immunocytochemistry analysis using (A, B) a combination of anti-vimentin (green), anti-neurofilament (red), ricin (blue), and Hoescht (white) and (C, D) a combination of anti-vimentin (green), anti-ezrin (red), ricin (blue), and Hoescht (white).

Notes: Figures (B and D) show the four channels separately for Figures (A and C), respectively. Mag Bars, (A, B): 50 microns; (C, D): I00 microns., a anti-vimentin was used to identify Müller cells (but could also show donor cells); anti-neurofilament was used to identify ganglion cell neurites; ricin was used to identify microglia and macrophages; anti-ezrin was used to identify retinal pigment epithelial cells (red arrows in part C); Hoescht was used to identify nuclei. ${ }^{b}$ Figures are projections of Z-stacks comprising 6 to 10 images taken at I-micron intervals.

safety of the cell product. Palucorcel, which is composed of hUTCs, does not require immune suppression for single or repeated administration to the subretinal space. In preclinical safety studies in miniature swine, a single administration of UTCs did not induce a detectable immune response. ${ }^{8,9}$ Furthermore, in an RCS model, palucorcel does not appear to differentiate, and there is no evidence of tumor formation. ${ }^{4}$ Retinal conditions and immune responses differ between animal models and human diseases; thus, there is a potential that palucorcel may have induced inflammatory and glial responses in subjects with RP in this early study, resulting in $\mathrm{RD}$ and the formation of an ERM. As clinical development of palucorcel has proceeded, the procedure and device used for subretinal delivery have been updated to reduce the risk for RD; results of clinical research using these new methods indicate that subretinal delivery of palucorcel is not associated with membrane development when delivered without retinal perforation. ${ }^{10}$ In this Phase I study, study surgeons delivered the cells into the subretinal space using a surgical procedure that involves a three-port pars plana vitrectomy, retinotomy, and transfer of the cells. Although these procedures are routinely performed, vitrectomy may be associated with severe complications, including RD or suprachoroidal hemorrhage, and the release of RPE cells may result in the formation of ERM or proliferative vitreoretinopathy. ${ }^{11-13}$ The formation of an ERM has been reported previously with other cell therapies delivered following vitrectomy. ${ }^{14,15}$ In this Phase I study of palucorcel delivered via a transvitreal route, two of seven subjects developed RD. Because of the very thin nature of the RP retina and the potential for palucorcel and RPE cells to egress through the retinotomy sites, leading to cellular 

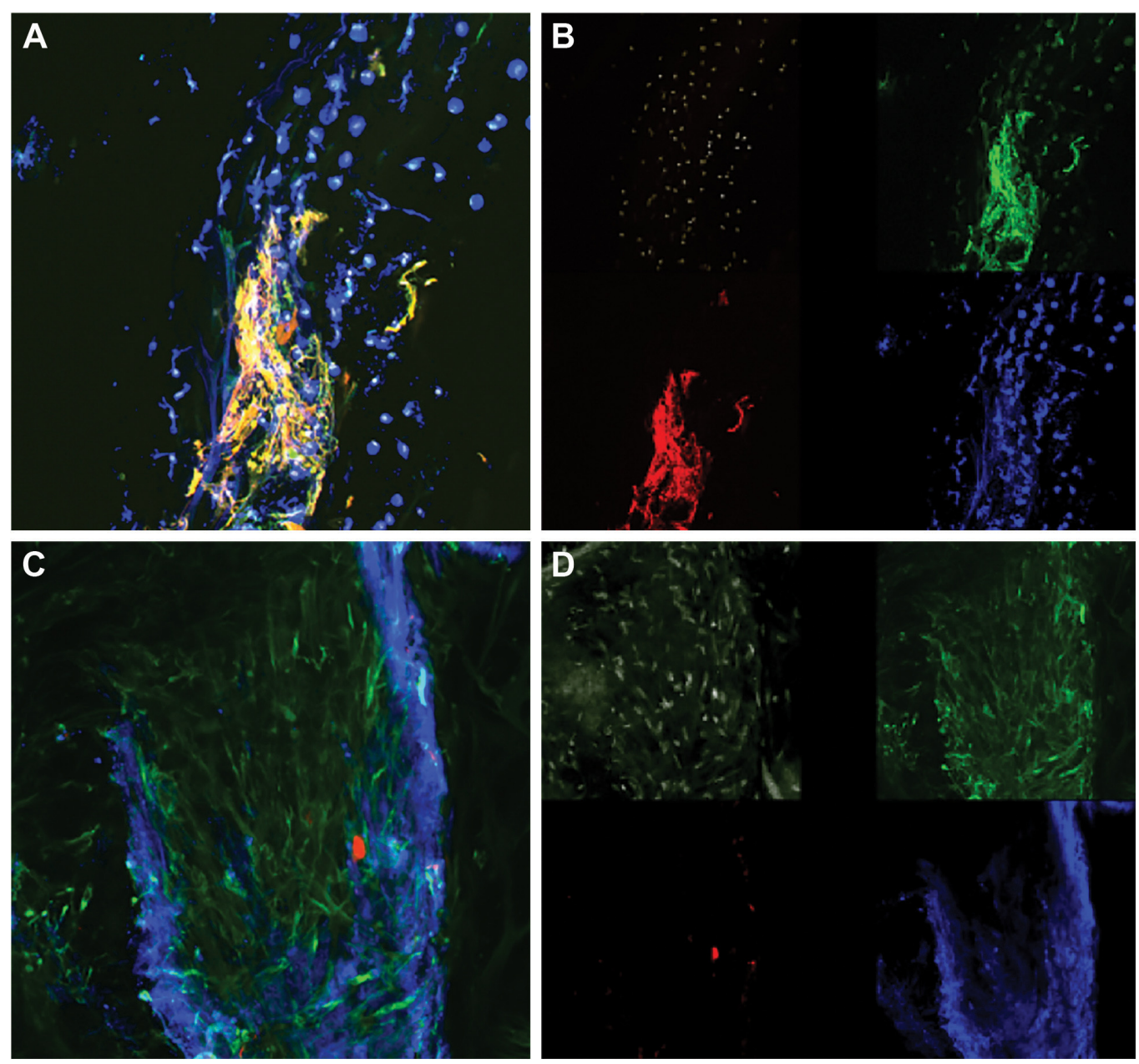

Figure 4 Epiretinal membrane immunocytochemistry analysis using (A, B) a combination of anti-vimentin (green), anti-GFAP (red), ricin (blue), and Hoescht (white) and (C, D) a combination of anti-vimentin (green), anti-Mibl (red), ricin (blue), and Hoescht (white).

Notes: Figures (B and $\mathbf{D})$ show the four channels separately for (A and C), respectively. Mag bars: (A, B): 100 microns; (C, D): 500 microns. ${ }^{\text {abb a }}{ }^{2}$ nti-vimentin was used to identify Müller cells (but could also show donor cells); anti-GFAP was used to identify glial cells; ricin was used to identify microglia and macrophages; Hoescht was used to

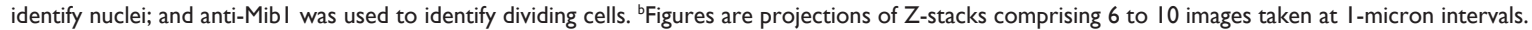

reactions in the vitreous, it is possible that the same trophic factors that are intended to stimulate retinal regeneration may contribute to ERM formation through recruitment of native cells. Given the risks associated with a retinotomy, the use of palucorcel as an adjunctive treatment for RP with this transvitreal delivery procedure was abandoned. Nevertheless, results in the RCS rat preclinical model indicated that palucorcel reduced the rate of retinal degeneration
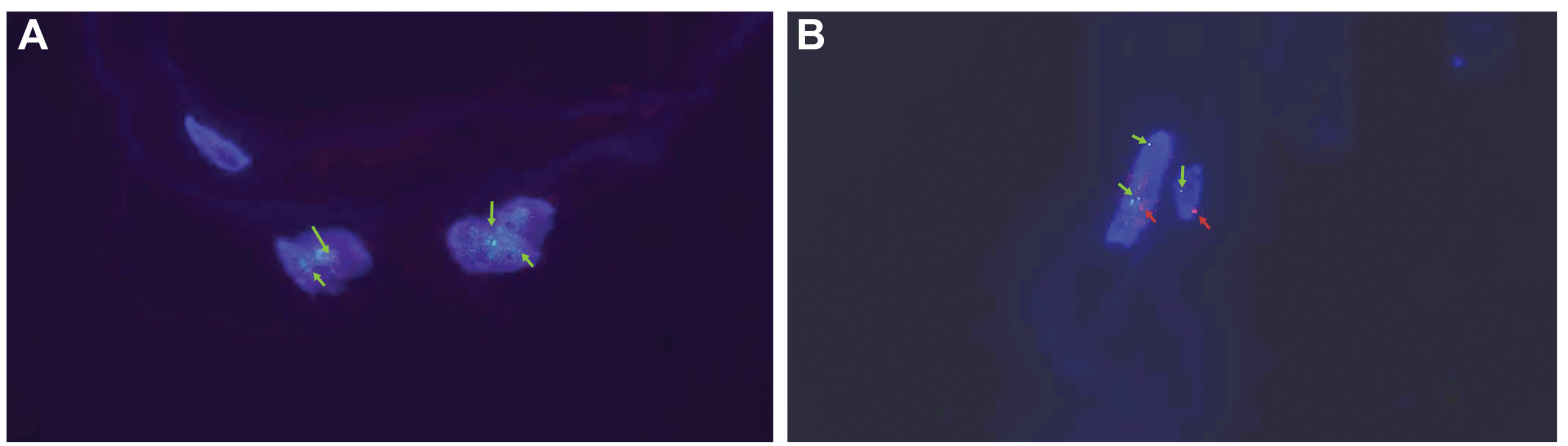

Figure 5 Fluorescence in situ hybridization staining of the epiretinal membrane using $(\mathbf{A})$ an $X$ (green arrows) chromosome probe and (B) $X$ (green arrows) and $Y$ (red arrows) chromosome probes. ${ }^{a}$

Note: ${ }^{\text {TT }}$ The nuclei in part $B$ are positive for both the $X$ (green arrows) and $Y$ (red arrows) chromosome probes. 
and vision loss; ${ }^{4}$ thus, alternative methods of palucorcel delivery have been evaluated to study its clinical effects in geographic atrophy associated with age-related macular degeneration.

Considering the small number of subjects in this Phase I study, we cannot draw definitive conclusions about a potential association of adverse outcomes with palucorcel, and it is not known if the risk for adverse outcomes, including the development of $\mathrm{RD}$, is dose related. Our findings do suggest that palucorcel has the potential to contribute to ERMs in the vitreous and that egress of RPE cells and palucorcel into the vitreous must be avoided. Thus, transvitreal delivery of these cells to the subretinal space is not a viable approach.

\section{Acknowledgments}

This work was supported by Janssen Research \& Development, LLC. TM, an employee of Janssen, and RS, SF, and GPL, who have received research funding from Janssen for this study, were involved in the development of the study design; collection, analysis, and interpretation of data; writing of the report; and in the decision to submit the article for publication. The authors thank Darin J. Messina, PhD, for contributions in performing the ERM analyses. Editorial support for the writing of this case report was provided by Megan Knagge, PhD, of MedErgy, and was funded by Janssen Research \& Development, LLC. The authors retained full editorial control over the content of the manuscript. All authors approved the final article.

\section{Disclosure}

TM is an employee of Janssen. RS, SF, and GPL received research funding from Janssen for this study. The authors report no other conflicts of interest in this work.

Clinical Ophthalmology

\section{Publish your work in this journal}

Clinical Ophthalmology is an international, peer-reviewed journal covering all subspecialties within ophthalmology. Key topics include: Optometry; Visual science; Pharmacology and drug therapy in eye diseases; Basic Sciences; Primary and Secondary eye care; Patient Safety and Quality of Care Improvements. This journal is indexed on

\section{References}

1. Sacchetti M, Mantelli F, Merlo D, Lambiase A. Systematic review of randomized clinical trials on safety and efficacy of pharmacological and nonpharmacological treatments for retinitis pigmentosa. JOphthalmol. 2015;2015:737053.

2. Ho AC. Human adult umbilical stem cells: potential treatment for atrophic AMD. Retina Today. 2011;7:59-61.

3. Strauss O, Stumpff F, Mergler S, Wienrich M, Wiederholt M. The royal college of surgeons rat: an animal model for inherited retinal degeneration with a still unknown genetic defect. Acta Anat (Basel). 1998; 162(2-3):101-111.

4. Lund RD, Wang S, Lu B, et al. Cells isolated from umbilical cord tissue rescue photoreceptors and visual functions in a rodent model of retinal disease. Stem Cells. 2007;25(3):602-611.

5. Wollensak G, Perlman EJ, Green WR. Interphase fluorescence in situ hybridisation of the $\mathrm{X}$ and $\mathrm{Y}$ chromosomes in the human eye. Br J Ophthalmol. 2001;85(10):1244-1247.

6. Oberstein SY, Byun J, Herrera D, Chapin EA, Fisher SK, Lewis GP. Cell proliferation in human epiretinal membranes: characterization of cell types and correlation with disease condition and duration. Mol Vis. 2011;17:1794-1805

7. Lewis GP, Betts KE, Sethi CS, et al. Identification of ganglion cell neurites in human subretinal and epiretinal membranes. Br J Ophthalmol. 2007;91(9):1234-1238.

8. Cho PS, Messina DJ, Hirsh EL, et al. Immunogenicity of umbilical cord tissue derived cells. Blood. 2008;111(1):430-438.

9. Lutton BV, Cho PS, Hirsh EL, et al. Approaches to avoid immune responses induced by repeated subcutaneous injections of allogeneic umbilical cord tissue-derived cells. Transplantation. 2010;90(5):494-501.

10. Ho AC, Chang TS, Samuel M, Williamson P, Willenbucher RF, Malone T. Experience with a subretinal cell-based therapy in patients with geographic atrophy secondary to age-related macular degeneration. Am J Ophthalmol. 2017;179:67-80.

11. Sadaka A, Giuliari GP. Proliferative vitreoretinopathy: current and emerging treatments. Clin Ophthalmol. 2012;6:1325-1333.

12. Vedantham V, Ramasamy K. Pigmented epiretinal membranes caused by RPE migration: OCT-based observational case reports. Indian J Ophthalmol. 2007;55(2):148-149.

13. Wang LC, Hung KH, Hsu CC, Chen SJ, Li WY, Lin TC. Assessment of retinal pigment epithelial cells in epiretinal membrane formation. J Chin Med Assoc. 2015;78(6):370-373.

14. Schwartz SD, Regillo CD, Lam BL, et al. Human embryonic stem cell-derived retinal pigment epithelium in patients with age-related macular degeneration and stargardt's macular dystrophy: follow-up of two open-label phase 1/2 studies. Lancet. 2015;385(9967):509-516.

15. Song WK, Park KM, Kim HJ, et al. Treatment of macular degeneration using embryonic stem cell-derived retinal pigment epithelium: preliminary results in Asian patients. Stem Cell Reports. 2015;4(5):860-872.
PubMed Central and CAS, and is the official journal of The Society of Clinical Ophthalmology (SCO). The manuscript management system is completely online and includes a very quick and fair peer-review system, which is all easy to use. Visit http://www.dovepress.com/ testimonials.php to read real quotes from published authors. 